\section{SAT0259 HIGH PLASMA CONCENTRATION OF MYCOPHENOLATE ACID IN EARLY PHASE OF INDUCTION THERAPY PREDICTS GOOD RENAL OUTCOME IN LUPUS NEPHRITIS CLASS III OR IV}

T. Kiyokawa, H. Hanaoka, H. lida, K. Ishimori, Y. Takakuwa, T. Okazaki, S. Ozaki. Division of Rheumatology and Allergology, Department of Internal Medicine, St. Marianna University School of Medicine, Kawasaki, Japan

Background: Mychophenolate mofetil (MMF) is recommended as initial induction treatment for most cases of lupus nephritis (LN) class III-IV. Although the association between area under the concentration-versus-time curve (AUC) of myochophenolate acid (MPA) and therapeutic efficacy has been well shown in renal transplantation, it has been poorly investigated in LN. Furthermore, MMF interacts with multiple factors and its concentration may be decreased by high prednisolone (PSL) dose, low serum albumin level and low creatinine clearance. Since these factors dramatically change in induction phase of LN, the plasma concentration of MPA may also change by fixed dose of MMF administration. Here, we measured $\mathrm{AUC}_{0-12}$ of MPA at different phases of induction treatment, early and middle, and prospectively investigated which concentration predicted future renal response in LN class III-IV.

Objectives: To investigate the relationship between the plasma concentration of MPA in early or middle phase of induction therapy and future renal response.

Methods: We prospectively enrolled patients with biopsy proven LN class III or IV who hospitalized from Apr to Oct 2016. As induction therapy, PSL was started at dose of $1 \mathrm{mg} / \mathrm{kg} /$ day and tapered to $10 \mathrm{mg} /$ day by 12 weeks. Fixed dose of MMF at $2,000 \mathrm{mg} /$ day was continuously introduced. We measured 2 points of MPA plasma concentration depending on the phase of induction therapy, at early (week 2) and middle (week 12). We evaluated the association between these concentration and complete renal response $(\mathrm{CR})$ rate at week 12 .

Results: Six patients were enrolled. $\mathrm{AUC}_{0-12}$ between the early and the middle phase was not correlated $\left(R^{2}=0.17, p=0.7\right)$, but that of the early phase tended to be lower ( $47.4 \pm 25.6$ vs $58.9 \pm 19.1 \mathrm{mgh} / \mathrm{L}$ ). All the patients with high $\mathrm{AUC}_{0-12}$ (over $40 \mathrm{mgh} / \mathrm{L}$ ) at the early phase achieved CR at week 12 (Figure 1). But we could not find any association between $\mathrm{AUC}_{0-12}$ at middle phase and $\mathrm{CR}$ rate at week 12 .

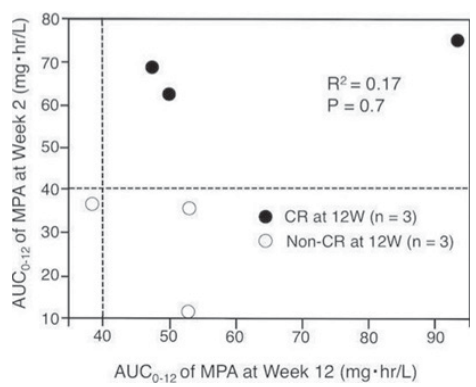

Figure 1

Conclusions: High $\mathrm{AUC}_{0-12}$ of MPA at the early phase of induction therapy might predict good renal response.

Disclosure of Interest: None declared

DOI: 10.1136/annrheumdis-2017-eular.4622

\section{SAT0260 OVARIAN FUNCTION PRESERVATION WITH GONADOTROPIN-RELEASING HORMONE ANALOGUES IN PATIENTS WITH SYSTEMIC LUPUS ERYTHEMATOSUS TREATED WITH CYCLOPHOSPHAMIDE}

V.A. Pacucci ${ }^{1}$, F. Ceccarelli ${ }^{1}$, G. Perrone ${ }^{2}$, I. Zannini ${ }^{2}$, M. Candelieri ${ }^{2}$, I. Leccese ${ }^{1}$, C. Perricone ${ }^{1}{ }^{1}$ F. Miranda $^{1}$, S. Truglia ${ }^{1}$, F.R. Spinelli ${ }^{1}$, C. Alessandri ${ }^{1}$ G. Valesini ${ }^{1}$, F. Conti ${ }^{1},{ }^{1}$ Lupus Clinic, Rheumatology, Dipartimento di Medicina Interna e Specialità Mediche; ${ }^{2}$ Gynecology, Dipartimento di Scienze Ginecologico-Ostetriche e Scienze Urologiche, Policlinico Umberto I Sapienza University of Rome, rome, Italy

Background: The fertility in childbearing Systemic Lupus Erythematosus (SLE) patients can be impaired due to several conditions. In particular, treatment with alkylating agents, as cyclophosphamide (CYC), could determine menstrual irregularities and premature ovarian failure (POF). Gonadotropin-releasing hormone analogues $(\mathrm{GnRH}-\mathrm{a})$ is one of the preventive strategy suggested by the recently published EULAR recommendations (1). They are characterized by good safety profile and effectiveness in reducing POF rate in patients with malignancies and autoimmune diseases. So far, only few studies have been published focusing on the use of $\mathrm{GnRH}$-a to prevent POF in SLE women receiving CYC treatment.

Objectives: In the present case-control study, we aimed at evaluating the efficacy of GnRH-a on the ovarian function preservation in SLE patients treated with CYC. Methods: We enrolled consecutive SLE patients, fulfilled the 1997 ACR revised criteria treated with $\mathrm{CYC}$ in the period between 2005 and 2012, receiving $\mathrm{GnRH}-\mathrm{a}$ $(\mathrm{GnRH}-\mathrm{a}+)$. As control, SLE patients treated with CYC not receiving $\mathrm{GnRH}-\mathrm{a}$ ( $\mathrm{GnRH}-\mathrm{a}-)$ were assessed. Clinical and laboratory data were collected in a standardized, computerized and electronically filled form. Ovarian function was assessed by the evaluation of FSH and estradiol level (E2). GnRH-a (triptorelin
$3.75 \mathrm{mg} /$ monthly intramuscularly) was prescribed. SLE patients treated with CYC were followed after the treatment every six months during the first year and then annually.

Results: Thirty-tree SLE patients treated by CYC were evaluated in the present analysis: $75.7 \%$ of patients were treated for lupus nephritis. Among [FC1] these, $18 \mathrm{GnRH}-\mathrm{a}+$ (mean $\pm \mathrm{SD}$ age $29.3 \pm 7.6$ years; mean $\pm \mathrm{SD}$ disease duration $7.2 \pm 4.2$ years) and $15 \mathrm{GnRH}-\mathrm{a}$ - (mean $\pm \mathrm{SD}$ age $31.0 \pm 10.5$ years; mean $\pm \mathrm{SD}$ disease duration $6.3 \pm 7.4$ years). The mean \pm SD SLEDAI-2K score in $\mathrm{GnRH}-\mathrm{a}+$ patients was $10.1 \pm 3.7$, in $\mathrm{GnRH}$-a- patients $8.3 \pm 3.3$ ( $\mathrm{p}=\mathrm{NS}$ ). Moreover, no differences were identified concerning the duration of CYC treatment (GnRH-a+: $6.1 \pm 2.8$ months versus $\mathrm{GnRH}-\mathrm{a}-6.1 \pm 2.2$ months, $\mathrm{p}=\mathrm{NS}$ ) and follow-up (GnRH-a+: $8.11 \pm 2.2$ years versus $\mathrm{GnRH}-\mathrm{a}-9.3 \pm 7.2$ years, $\mathrm{p}=\mathrm{NS}$ ). The prevalence of $\mathrm{POF}$ was significantly higher in $\mathrm{GnRH}$-a- (5 patients, 33.3\%) in comparison with $\mathrm{GnRH}-\mathrm{a}+(2$ patients, $11.1 \%, P=0.0002)$. A significantly higher mean age at the time of CYC treatment was observed in patients developing POF $(37.7 \pm 5.9$ years $)$ in comparison with those not developing this complication $(28.0 \pm 8.5$ years, $p=0.008)$. Moreover, the use of $\mathrm{GnRH}$-a seems to be protective also in terms of menstrual cycle regularity: the cycle remained regular during treatment in $83.3 \%$ of $\mathrm{GnRH}-\mathrm{a}+$ and only in $33.3 \%$ of $\mathrm{GnRH}-\mathrm{a}-(\mathrm{p}=0.003)$. During the follow-up, 3 patients in the $\mathrm{GnRH}-\mathrm{a}+$ group underwent pregnancy, with a good outcome.

Conclusions: The results of the present study showed the protective role of GnRH-a for the preservation of ovarian function in SLE patients treated by CYC. Furthermore, the age resulted the only risk factor associated with POF development.

References:

[1] Andreoli L. et al. Ann Rheum Dis. 2016 Jul 25.

Disclosure of Interest: None declared

DOI: 10.1136/annrheumdis-2017-eular.6381

\section{SAT0261 REFRACTORY SYSTEMIC LUPUS ERYTHEMATOSUS IS MAINLY ASSOCIATED WITH THE DECREASED NUMBER OF REGULATORY T CELLS AND LOW-DOSE IL-2 COMBINED WITH RAPAMYCIN CAN EFFICIENTLY RECOVERY THE BALANCE OF TH17/REGULATORY T CELLS}

X. Jing ${ }^{1}$, X. Liu ${ }^{1}$, J. Wang ${ }^{1}$, Y. Qiao ${ }^{1}$, Z. Liang ${ }^{1}$, M. Hao ${ }^{1}$, J. Chen ${ }^{1}$, C. Gao ${ }^{2}$, X. Li ${ }^{1} .{ }^{1}$ Department of Rheumatology, The Second Hospital of Shanxi Medical University, Taiyuan, China; ${ }^{2}$ Department of Pathology, Joint Program in Transfusion Medicine, Brigham and Women's Hospital/Children's Hospital Boston, Harvard Medical School, Boston, United States

Background: Refractory system lupus erythematosus (SLE) still relies on aggressive treatment with high-dose glucocorticoids and immunosuppressive agents,but a significant proportion of patients persist with activity or relapse and show serious side-effects by the treatment.However, the imbalance of Th17 cells and regulatory $T$ (Treg) cells in peripheral blood of patients with SLE may be an important factor in the pathogenesis of SLE.Because low-dose IL-2 can selectively enhance Treg function while avoiding the activation of effector T cells and rapamycin can promote the proliferation of Treg cells ${ }^{1-2}$, the combination of the low-dose IL-2 and rapamycin has been considered to treat refractory SLE for the purpose of remission.

Objectives: To observe the effect of low-dose IL-2 combined with rapamycin on the balance of Th17/Treg cells in patients with refractory SLE.

Methods: Eighty-two refractory SLE patients (80 women and 2 men), with a mean duration of $72.41 \pm 37.52$ months and mean age of $36.22 \pm 12.48$ years, were enrolled.They are in line with the standard of ACR in 1997,who are treated with glucocorticoid and immunosuppressant for more than one year, but the subjects continues to rise to a peak.After the eligible patients are given IL-2 and rapamycin in combination therapy with conventional therapy at $0,6,12,24$ week respectively after medication. The clinical symptoms, blood routine, urine routine, ESR, Th17 cells, Treg cells, Th17/Treg cells and the dosage of corticosteroids and immunosuppressant are registered one by one.

Results: At 24 week after treatment,28.9\% patients with refractory SLE were relieved.Low-dose IL-2 combined with rapamycin leaded to an increase in the absolute counts of Treg cells in refractory SLE patients, from a median of 12.98 cells/ul (at week 0) to 22.1 cells/ul (at week 24) $(P=0.002)$. The ratio of Th17/Treg cells shows a reduction from a median of 0.44 at week 0 to 0.29 at week $24(\mathrm{P}=0.029)$. No significant difference was observed in the absolute counts of Th17 after combined treatment.At week 24, the mean dosage of prednisone which refractory SLE patients were receiving decreased from $17.20 \mathrm{mg} / \mathrm{d}$ to 8.87 $\mathrm{mg} / \mathrm{d}$. And the categories of DMARDs use were also reduced $(P<0.05)$.

Conclusions: Our results suggest that refractory SLE is major associated with the decreased number of Treg but not that of Th17.The Th17 and Treg cells in the peripheral blood of patients with refractory SLE tends to balance due to the significantly increase the number of Treg cells after low-dose IL-2 combined with rapamycin treatment.Low-dose IL-2 combined with rapamycin treatment can reduce the dosage of glucocorticoid and DMARDs.

References:

[1] Liao, W.,Lin, J. X. \& Leonard,W. J.Interleukin-2 at the crossroads of effector responses, tolerance, and immunotherapy. Immunity 38,13-25 (2013).

[2] Tomasoni R, Basso V, Pilipow K, etal.Rapamycin-sensitive signals control RCR/CD28-driven Ifng,I14and Foxp3 transcription and promoter region methylation.Eur J Immunol,2011,41:2086-2096. 